\title{
Dates, Caries, and Early Tooth Loss During the Iron Age of Oman
}

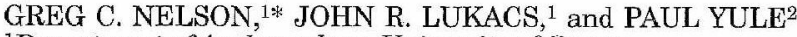 \\ ${ }^{1}$ Department of Anthropology, University of Oregon, \\ Eugene, Oregon 97403-1218 \\ 2 Ruprecht-Karls-Universität-Heidelberg \\ Am Büchel 77, D-5300 Bonn, Germany
}

\begin{abstract}
KEY WORDS dental caries formation; antemortem tooth loss; Arabian peninsula
\end{abstract}

\begin{abstract}
Diets high in fermentable carbohydrates are known to be highly cariogenic, particularly when contained in very sticky food such as dates. This medium allows food to remain in contact with the teeth, thereby resisting the normal flushing action of the saliva. When comprising a large portion of the diet, food such as this can lead to high caries incidence and accelerated tooth loss. This appears to be the situation found in a skeletal series from the late Iron Age in the Sultanate of Oman (100 BC-AD 893).

Dental remains from 37 individuals were used in this study. Antemortem tooth loss (AMTL), caries, and dental attrition data were compiled from the 32 adult and juvenile specimens.

In this sample, the caries rate is $35.5 \%$ of individuals ( $39.4 \%$ corrected), and $18.4 \%$ of teeth (32.4\% corrected), while AMTL occurs in $100 \%$ (ten of ten) of preserved mandibles. Caries onset in permanent molars begins soon after eruption, with tooth loss and remodeling of the alveolus frequently complete by the time of third molar occlusion. Am J Phys Anthropol 108:333-343, 1999. (1999 Wiley-Liss, Inc.
\end{abstract}

Despite concerns over the accuracy and reliability of observation and reporting of dental lesions (Jackes and Lubell, 1995; Lukacs, 1995), the general relationship between dental pathology and diet has been well established (Stephan, 1966; Powell, 1985; Lukacs, 1989; Larsen et al., 1991). A consistent finding is that foods high in fermentable carbohydrates are an important agent in the etiology of caries (Mandel, 1979; Newbrun, 1982) and the resultant antemortem tooth loss (AMTL) (Featherstone, 1987). One area that offers an opportunity for the study of these pathological conditions is the Arabian Peninsula and the early oasis settlements located there. Dates, a food high in fermentable carbohydrates, are easily grown in the oases and have been a segment of the local diet since at least $3000 \mathrm{BC}$ (Tosi, 1986; Cleuziou and Tosi, 1989; Potts, 1993).
Previous studies of skeletal series from the Arabian peninsula have highlighted the negative impact of date consumption on dental health (Hojgaard, 1980a,b; Kunter, 1983; Littleton and Frohlich 1989, 1993). In this report, we present results of investigations of new material from the late Iron Age cemeteries around Samad oasis, Oman, in which the rate of AMTL exceeds any previously reported for the Arabian peninsula, while caries frequencies, although high, fall within the range of contemporary material. Important in this Samad series is the apparent early age at which caries-induced AMTL occurs. Frequently first permanent molars are lost and alveolar remodeling complete

\footnotetext{
*Correspondence to: Greg C. Nelson, Department of Anthropology, University of Oregon, Eugene, OR 97403-1218.

Received 5 March 1997; accepted 11 November 1998.
} 
by the time the third molars come into occlusion. So extreme is the AMTL that all adult individuals in which mandibular corpi are present had lost teeth before death.

Furthermore, in addition to adding to the relatively scant database of human dental material from the Arabian peninsula, this study employs the caries correction factor (Lukacs, 1992, 1995) as a means of more accurately reporting caries rates and evaluates its utility in studies where small sample size may be a problem.

\section{MATERIALS AND METHODS}

Samad oasis is $140 \mathrm{~km}$ south of Muscat, the capitol of Oman, at an elevation of 540 $\mathrm{m}$. There is a long history of excavations in and around the Wadi Samad, within which both Samad oasis and its close neighbor Maysar oasis lie (Humphries, 1974; Hastings et al., 1975; Doe, 1977; Vogt, 1984; Potts, 1993). Previously excavated skeletal material from the Samad area has been analyzed (Kunter, 1981, 1983) and recently reanalyzed (Littleton and Frohlich, 1993).

The material examined in this study was excavated during the 1980 s by the German Archaeological Mission to the Sultanate of Oman under the direction of one of us (P.Y.). It consists of dental and gnathic remains of 37 individuals from the Samad culture of the late Iron Age which spans the time from 100 $\mathrm{BC}$ to AD 893 (Yule, 1993). Preservation ranges from moderate to poor, and in several instances individual specimens consist merely of a few teeth. Due to the fragmentary nature of the material, sex determination was impossible, and age classifications are relatively broad, as they are based solely on dental development and wear.

Each permanent tooth was examined for caries, with both lesion location and size recorded. Only those individuals with erupted permanent teeth were used in the caries analysis, thereby excluding one edentulous individual and five individuals whose age at death was less than five. Antemortem tooth loss was determined by examining the bony elements for remodeling. For the ten mandibuli and three maxillae present in the sample, this was relatively easy, as few teeth were lost postmortem and remodeling in
Observed Caries Rate $=$

$$
\frac{\text { number of carious teeth (26) }}{\text { total number of teeth observed (141) }}=18.44 \%
$$

Corrected Caries Rate $($ Lukacs, 1992, 1995) $=$

1) Estimated number of teeth lost due to caries.

[number of teeth lost antemortem (41)] $\mathrm{x}$ [proportion of teeth with pulp exposure due to caries $(8 / 10 ; 80.0 \%)]=33$

2) Total estimated number of teeth with caries.

[estimated number of teeth lost due to caries (33)] + [number of carious teeth observed (26)] $=59$

3) Total number of original teeth.

[number of teeth observed (141)] + [number of teeth lost $\operatorname{antemortem}(41)]=182$

4) Corrected caries rate.

[total estimated number of teeth with caries (59)] [total number of original teeth (182)] $=32.42 \%$

Fig. 1. Steps used in calculating the caries correction factor. From Lukacs (1995).

most instances was either complete or nearly so. Erupted permanent teeth were scored for wear following the methodologies of Scott (1979) for molars and Molnar (1971) for incisors, canines, and premolars. Pulp exposure was noted as to cause (either caries or wear induced) for calculation of the caries correction factor (Lukacs, 1992, 1995) (Fig. 1), which, because of the high rates of AMTL, was used to produce a more realistic picture of caries frequencies in the Samad sample. Analyses of caries and AMTL rates were done on both an individual and tooth-count basis. To see if the high rates of caries and AMTL are meaningful, we used $\chi^{2}$ and Fisher exact tests to compare the observed toothcount caries and AMTL rates with a comparative sample. The comparative sample is limited to Arabian peninsula, European, and Asian sites that consistently reported three variables: AMTL and individual and toothcount caries rates. To help determine if tooth extraction was practiced by the Iron Age residents of Samad, we made radiographs of mandibuli to see if any root tips remained in the bone. 
$T A B L E$ 1. Caries and antemortem tooth loss rates for Samad Oasis and a comparative sample, by percentage

\begin{tabular}{|c|c|c|c|c|c|}
\hline Group & Period & $\begin{array}{l}\text { Individual caries } \\
\text { (n) }\end{array}$ & $\begin{array}{l}\text { Tooth count } \\
\text { caries }(\mathbf{n})\end{array}$ & $\begin{array}{c}\text { Antemortem tooth } \\
\text { loss }(n)\end{array}$ & Reference \\
\hline Samad oasis & Iron Age & & & $90.9(11)$ & This study \\
\hline $\begin{array}{l}\text { Observed } \\
\text { Corrected }\end{array}$ & & $\begin{array}{l}35.5(31) \\
39.4(33)\end{array}$ & $\begin{array}{l}18.4(141) \\
32.4(182)\end{array}$ & & \\
\hline Failaka & Iron Age & $85.7(9)$ & $5.3(207)$ & $50.0(8)$ & Littleton and Frohlich (1993) \\
\hline Bahrain & Bronze Age & $49.0(75)$ & $13.3(308)$ & $75.4(69)$ & Littleton and Frohlich (1989) \\
\hline Bahrain & Iron Age & $35.5(129)$ & $17.2(495)$ & $77.6(98)$ & Littleton and Frohlich (1989) \\
\hline Bahrain & Early Islamic & $83.3(38)$ & $14.0(471)$ & $76.0(25)$ & Littleton and Frohlich (1989) \\
\hline Um an-Nar & Bronze Age & $21.6(37)$ & $2.4(327)$ & $33.7(?)$ & Littleton and Frohlich (1993) \\
\hline Harappa & Bronze Age & $43.6(39)$ & $6.8(751)$ & $31.7(41)$ & Lukacs (1992) \\
\hline Sarai Khola I & Iron Age & $30.0(10)$ & $4.7(177)$ & $33.0(9)$ & Lukacs et al. (1989) \\
\hline Sarai Khola II & Iron Age & $62.0(26)$ & $4.4(671)$ & $42.0(26)$ & Lukacs et al. (1989) \\
\hline Mehrgarh & Neolothic & $9.0(89)$ & $1,4(1273)$ & $22.9(48)$ & Lukacs and Minderman (1992) \\
\hline Mehrgarh & Chalcolithic & $23.2(69)$ & $3.4(865)$ & $29.4(34)$ & Lukacs and Minderman (1992) \\
\hline Timargarha & Iron Age & $34.9(83)$ & $7.2(615)$ & $32.0(50)$ & Lukacs et al. (1989) \\
\hline Mahurjhari & Iron Age & $53.3(15)$ & $7.7(196)$ & $7.7(13)$ & Lukacs et al. (1989) \\
\hline Mahadaha & Mesolithic & $28.6(14)$ & $1.2(261)$ & $26.7(15)$ & Lukacs and Hemphill (1992) \\
\hline Damdama & Mesolithic & $14.3(35)$ & $0.9(800)$ & $28.6(35)$ & Lukacs and Pal (1993) \\
\hline Yugoslavia & Mesolithic & $0.0(42)$ & $0,0(705)$ & $24.0(42)$ & y'Edynak (1992) \\
\hline Yugoslavia & Neolithic & $6.0(17)$ & $0.5(190)$ & $0.0(17)$ & y'Edynak (1992) \\
\hline Portugal & Mesolithic & $40.3(27)$ & $6.7(1300)$ & $22.4(15)$ & Frayer $(1988)$ \\
\hline
\end{tabular}

\section{RESULTS \\ Caries frequency}

Caries frequencies for Samad are shown in Table 1. Although generally grouped with material from sites considered to be early agricultural, there are differences in the relative position of the Samad series depending on whether one is looking at rates for individuals or teeth. The individual-count caries rate for Samad $(35.5 \%$; $39.4 \%$ corrected) falls near the midpoint of the comparative sample shown in Figure 2. Here Samad lies in a cluster of Iron Age sites (Sarai Khola I, Timargarha, and Iron Age Bahrain) with similar frequencies but well below the three other Iron Age sites of Mahurjhari, Sarai Khola II, and Failaka. However, when viewed from the perspective of tooth-count caries frequencies (Fig. 3 ), the Samad rate of $18.4 \%$ ( $32.4 \%$ corrected) is the most extreme of all groups in the comparative sample, with the corrected rate being nearly twice that of the next highest, Iron Age Bahrain.

The disparity between the relative placement of the individual and tooth-count rates can probably be traced to the fragmentary nature of the Samad material. As noted, several individuals are represented by only a few teeth, possibly skewing results in favor of one or the other measures. In a attempt to rectify this, we reevaluated the material using only those specimens with more than two teeth present. When this is done, the observed tooth-count rate rises only slightly to $20 \%(35.1 \%$ corrected), whereas the individual rate climbs to $75 \%$ ( $78.6 \%$ corrected). This latter figure is probably a better reflection of the individual caries frequencies for Samad, as it corresponds to the extremely high rates for both tooth-count caries and antemortem tooth loss.

The relationship between observed and corrected tooth-count caries rates from $\mathrm{Sa}$ mad fits the pattern seen with other dental series in which the caries correction factor has been utilized. At Samad, the corrected rate of $32.4 \%$ is nearly double the observed rate of $18.4 \%$, a difference similar to what Lukacs (1995) found for groups practicing intensive agriculture. In Figure 3, the intensive agricultural sites of Chalcolithic Mehrgarh and Bronze Age Harappa exhibit the same relative differences between corrected and observed caries rates as Samad, while the early agricultural site of Neolithic Mehrgarh shows a much smaller difference.

Table 2 reports the $\chi^{2}$ and Fisher exact test results. For tooth-count caries, the Samad sample exhibits significantly higher rates than all except the Bahrainian samples. 


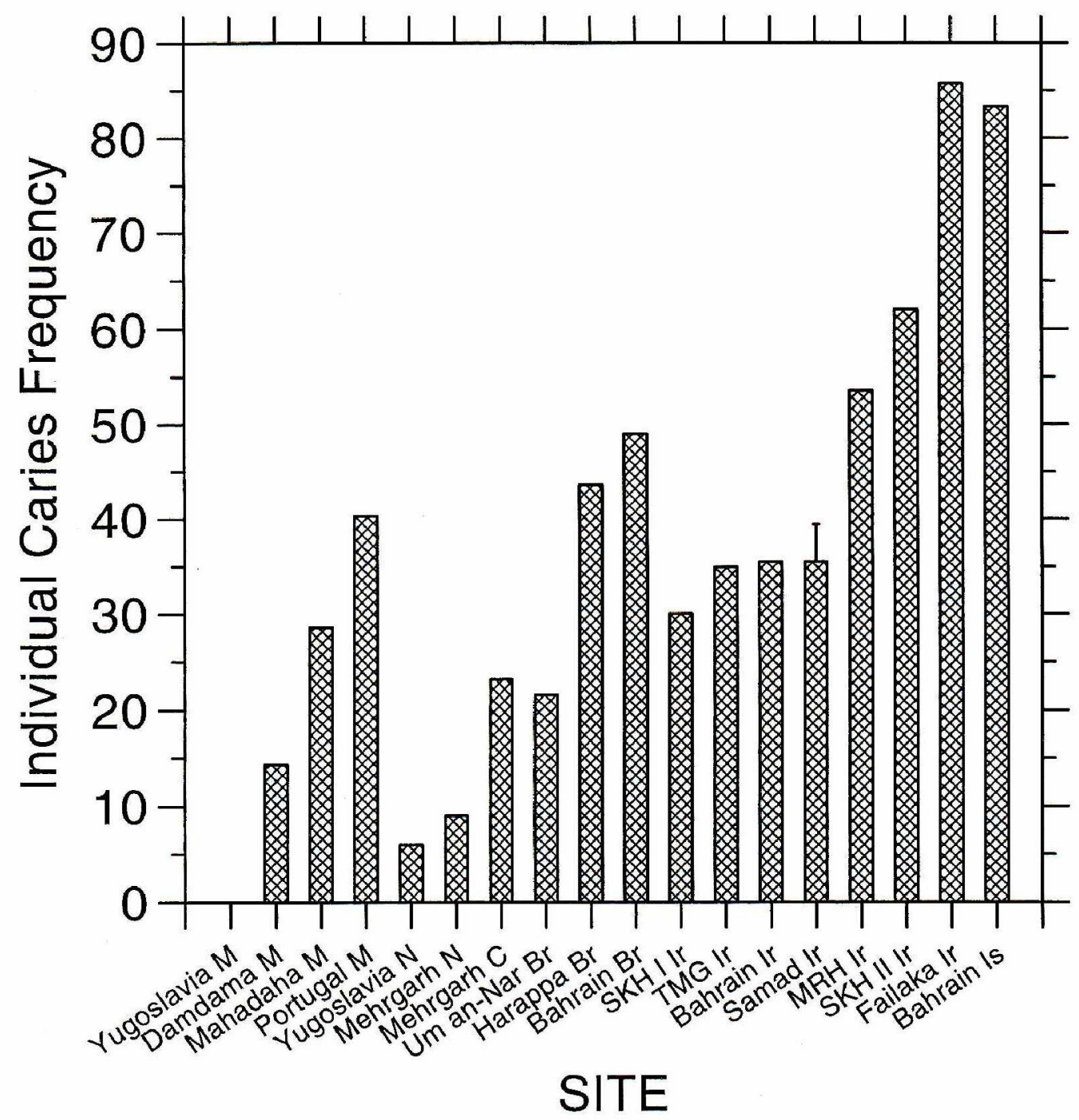

Fig. 2. Individual-count caries rates for Samad oasis and a comparative sample grouped by time period. Error bar is corrected caries rate. Br, Bronze Age; C, Chalcolithic; Ir, Iron Age; Is, Islamic; M, Mesolithic; MRH, Mahurjhari; N, Neolithic; SKH, Sarai Khola; TMG, Timargarha.

\section{Antemortem tooth loss}

Antemortem tooth-loss rates for the Samad series are very high, at $91 \%$ of all individuals with gnathic remains and $100 \%$ of mandibles (Table 1). As can be seen in Figure 4, these are the highest among those of the comparative sample. Statistical analysis reveals a pattern similar to that found for tooth-count caries (Table 2). For AMTL, Iron Age Failaka joins the Bahrainian samples as the only sites that show no significant difference in occurrence frequency (Fisher $P=0.111$ is probably a more realistic estimate because of small sample size).
Mandibular radiographs show that root tips are not present in the alveolar bone (Fig. 5). This finding contrasts with Hojgaard's (1980b) result for Bahrain, where she found several examples of root tips remaining in jaws. Although not conclusive evidence against tooth extraction at Samad, it is a good indication that it did not occur in these specimens.

\section{Dental wear}

Twenty-nine permanent molars were available for scoring wear. Only those which had erupted were included in this portion of 


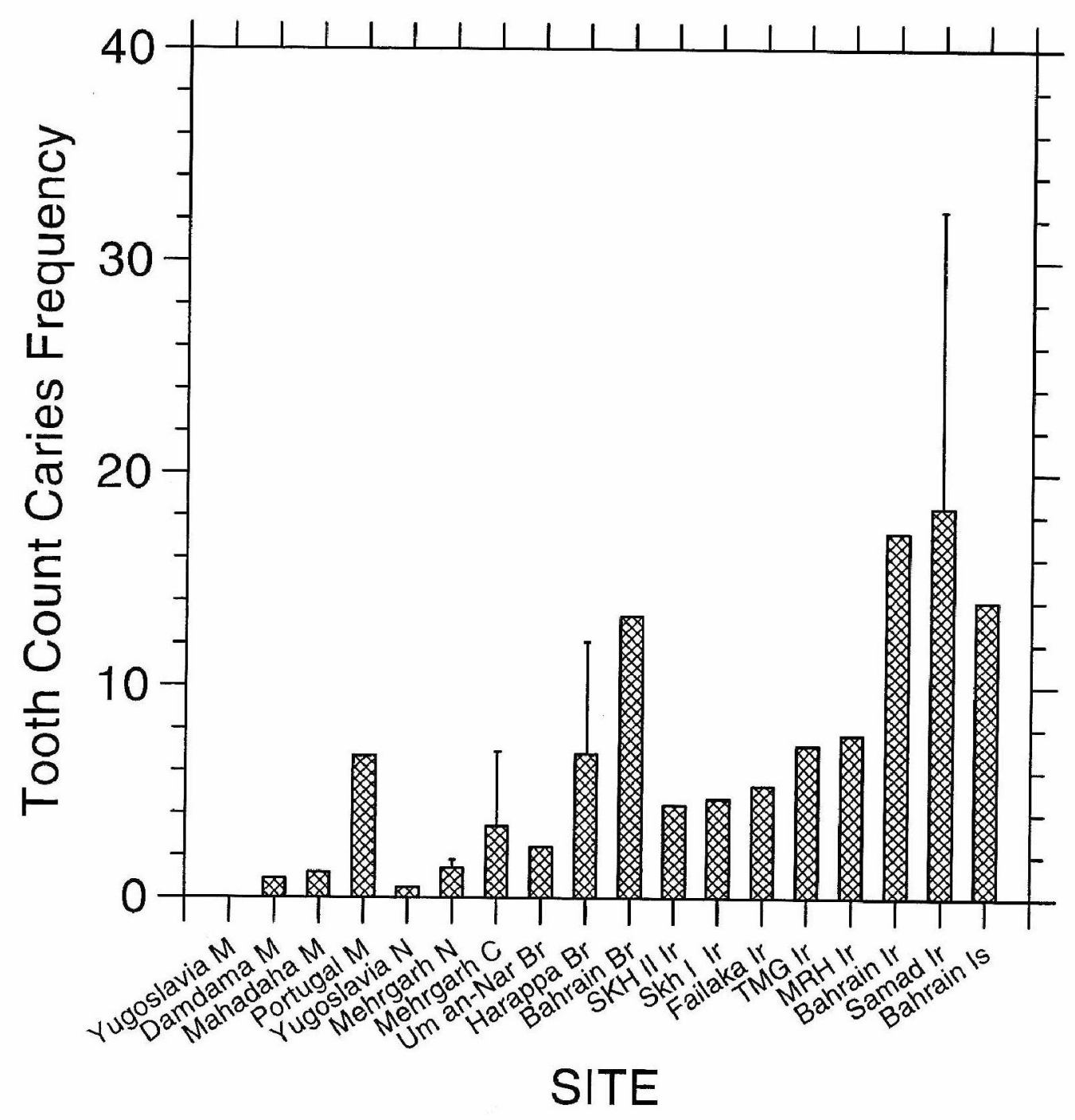

Fig. 3. Tooth-count caries rates for Samad oasis and a comparative sample grouped by time period. Error bars are corrected caries rates. See Fig. 2 for abbreviations.

the study. Wear scores for Scott's (1979) method range from 4 to 40 , with 4 indicating little or no discernable wear. Twelve of the 29 molars $(41 \%)$ from this sample were scored at the minimum of 4 , and the remainder scored no higher than 13. This indicates that dental attrition was very slight overall for the Iron Age Samad peoples. In several instances, dental eruption was complete (third molars fully erupted) but wear minimal. This light molar wear can be attributed in part to the early loss of occluding molars. This can be seen in the two individuals with the highest wear score of $12\left(\mathrm{LM}_{3}\right.$ of speci- men 586) and $13\left(\mathrm{RM}_{2}\right.$ of specimen 575$)$. In each case, other molars remaining in the arcade are not nearly as worn, quite possibly indicating that the more heavily worn tooth was the only one still occluding with its maxillary isomere.

In contrast to molar wear, incisor and canine wear is relatively heavy. When we used Molnar's (1971) method, based on a scale of 1 (little or no wear) through 8 (extreme wear), the 22 incisors averaged 3.55 , ranging from 1-6. For the 21 available canines, the average wear is 3.5 , with a range of 1-7. The premolars show less wear 
TABLE 2. $\chi^{2}$ and Fisher exact test results: Samad compared to other Arabian Peninsula and non-Arabian Peninsula sites

\begin{tabular}{|c|c|c|c|c|c|c|}
\hline \multirow[b]{3}{*}{ Site } & \multicolumn{3}{|c|}{ Tooth count caries } & \multicolumn{3}{|c|}{ Antemortem tooth loss } \\
\hline & \multicolumn{2}{|c|}{$x^{2}$} & \multirow[b]{2}{*}{ Fisher $P$} & \multicolumn{2}{|c|}{$\chi^{2}$} & \multirow[b]{2}{*}{ Fisher $F$} \\
\hline & Value & $P$ & & Value & $P$ & \\
\hline Failaka & 15.207 & 0.000 & 0.000 & 3.997 & 0.046 & 0.111 \\
\hline Bahrain Bronze Age & 2.003 & 0.157 & 0.157 & 1.135 & 0.252 & 0.441 \\
\hline Bahrain Iron Age & 0.112 & 0.726 & 0.708 & 1.060 & 0.303 & 0.452 \\
\hline Bahrain Islamic & 1.665 & 0.197 & 0.226 & 1.084 & 0.298 & 0.400 \\
\hline Um an-Nar & 37.404 & 0.000 & 0.000 & na & na & na \\
\hline Harappa & 20.424 & 0.000 & 0.000 & 12.323 & 0.001 & 0.001 \\
\hline Sarai Khola I & 13.713 & 0.000 & 0.000 & 7.213 & 0.007 & 0.017 \\
\hline Sarai Khola II & 36.267 & 0.000 & 0.000 & 7.439 & 0.006 & 0.010 \\
\hline Mehrgarh Neolithic & 122.049 & 0.000 & 0.000 & 18.047 & 0.000 & 0.000 \\
\hline Mehrgarh Chalcolithic & 53.395 & 0.000 & 0.000 & 12.730 & 0.000 & 0.001 \\
\hline Timargarha & 17.387 & 0.000 & 0.000 & 12.794 & 0.000 & 0.001 \\
\hline Mahurjhari & 8.929 & 0.003 & 0.004 & 16.620 & 0.000 & 0.000 \\
\hline Mahadaha & 40.887 & 0.000 & 0.000 & 10.539 & 0.001 & 0.002 \\
\hline Damdama & 109.290 & 0.000 & 0.000 & 13.235 & 0.000 & 0.000 \\
\hline Yugoslavia Mesolithic & 134.122 & 0.000 & 0.000 & 16.704 & 0.000 & 0.000 \\
\hline Yugoslavia Neolithic & 34.667 & 0.000 & 0.000 & 24.040 & 0.000 & 0.000 \\
\hline Portugal Mesolithic & 24.290 & 0.000 & 0.000 & 20.370 & 0.000 & 0.000 \\
\hline
\end{tabular}

than the incisors and canines, decreasing from 2.5 for P3s $(\mathrm{n}=20)$ to 2.07 for the 14 P4s.

\section{DISCUSSION}

Dates have been an important part of agriculture in the Arabian peninsula for the last 5,000 years. By using date palms for shade and graberband (flood) or falaj (aqueduct) irrigation for water, early agriculturists created microclimates where they were able to plant gardens in what otherwise would be a very harsh environment (Costa, 1980; Tosi, 1986; Frifelt, 1989; Potts, 1993). The earliest evidence for this type of oasis farming comes from Hili 8 at the $\mathrm{Al}$-ain oasis, United Arab Emirates, and dates to about 3000 BC. Here, along with charred date stones, seeds from grains such as wheat, barley, and sorghum are found (Tosi, 1986; Potts, 1993). In the area of the Wadi Samad there is also early evidence for oasis farming. Wells and evidence of fields date from late third millennium $\mathrm{BC}$ Bronze Age sites at Maysar (Berthoud and Cleuziou, 1980; Frifelt, 1989), and traces of graberbands, also dating to the third millennium $\mathrm{BC}$, have been found at Samad (Hastings et al., 1975). In fact, oasis farming using the falaj system is still in use at Samad (Hastings et al., 1975) and other oases in Oman (Frifelt, 1989).
Stephan (1966), in a study of rats fed a controlled diet, has shown that dates are highly cariogenic. Of the 52 food substances tested, dates were the seventh most cariogenic and ranked the highest of the unprocessed foods. It is not surprising, therefore, that people living in the shade of extensive date palm groves and not practicing modern dental hygiene were highly susceptible to dental caries. Even the modern inhabitants of Samad oasis are noted to have extremely poor dental health due to the consumption of dates (Kunter, 1981). The correlation between the consumption of dates and dental pathology has been discussed often in investigations dealing with the early inhabitants of the Arabian Peninsula. Littleton and Frohlich $(1989,1993)$ tie the eating of dates to high caries rates and AMTL in Bronze and Iron Age Bahrain, as does Hojgaard (1980b), who notes that 16 of 18 mandibuli had AMTL of either $\mathbf{M}_{1}$ or $\mathbf{M}_{2}$. At Shimal, a late Bronze Age site on the Persian Gulf coast of the Oman peninsula, Vogt et al. (1989:66) attribute high AMTL to "heavy carious infection," with, although not stated, dates being a logical cause, as they have a long history in the area and are currently grown at the site.

The deleterious nature of a diet high in fermentable carbohydrate content is reemphasized by the extremely high caries rates 


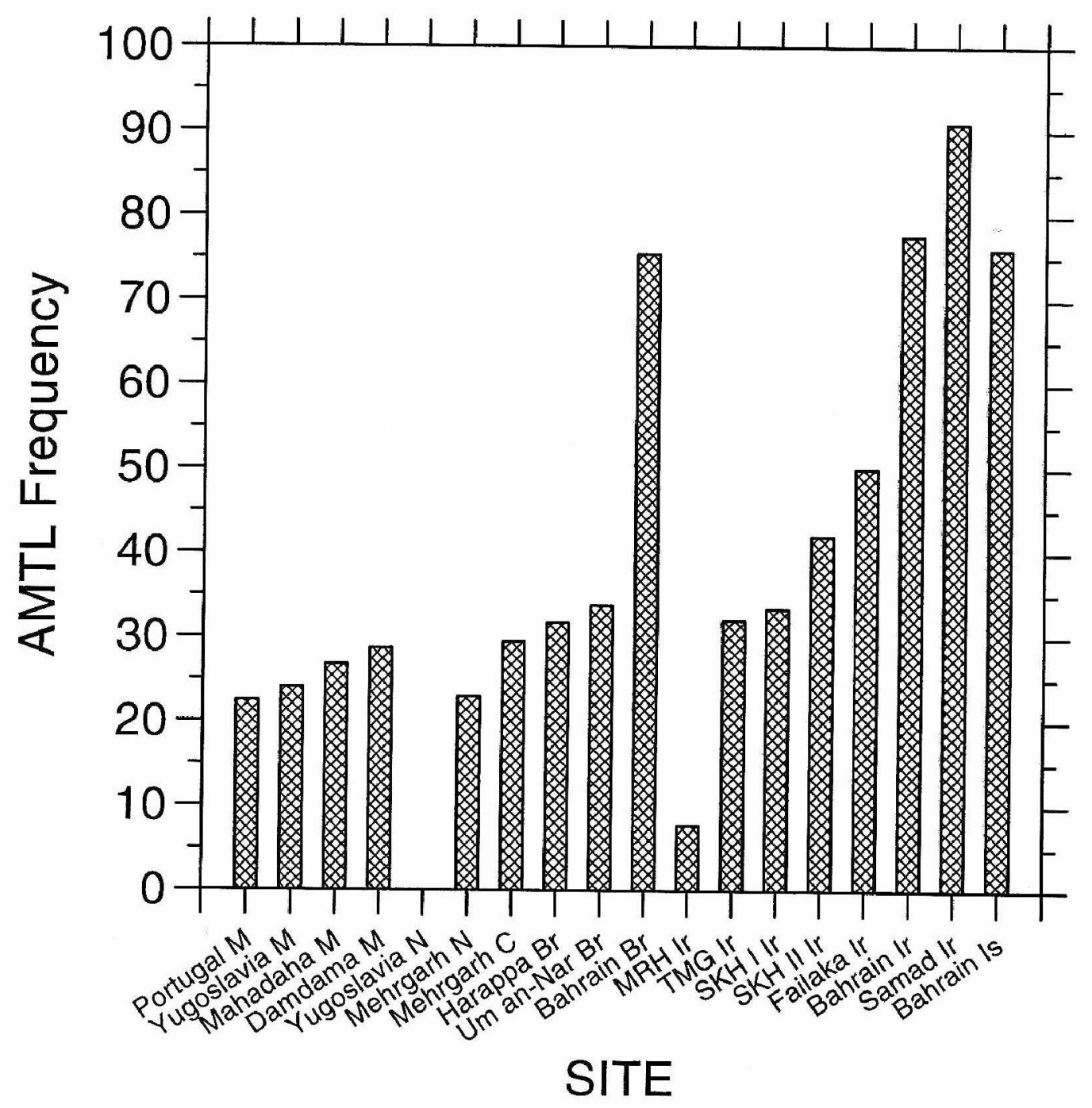

Fig. 4. Antemortem tooth loss rates for Samad oasis and a comparative sample grouped by time period. See Fig. 2 for abbreviations.

that result from implementation of the caries correction factor. As the Samad sample is both fragmentary and relatively small (141 teeth, or four teeth per individual) compared to other samples to which the correction factor has been applied (751 teeth and 19 per individual for Harappa, 865 and 13 for Chalcolithic Mehrgarh, and 1,273 and 14 for Neolithic Mehrgarh), it is important to note that these factors do not seem to affect its use or the validity of the results. As long as the tallying of antemortem tooth loss and frequency of caries vs. attrition causation is accurate, sample size should not be a factor unless it drops below an acceptable level for statistical analysis.

One aspect of AMTL that seems to be common to sites where dates are a prevalent cause of dental pathology is the early age of initial tooth loss. In addition to Samad, the material from Bahrain indicates that early onset of caries and subsequent tooth loss was widespread (Hojgaard, 1986; Littleton and Frohlich, 1989, 1993). The dental material from Samad has excellent examples of the various stages of carious decay leading up to tooth loss. First, a juvenile of approximately 10 years of age already has extensive 

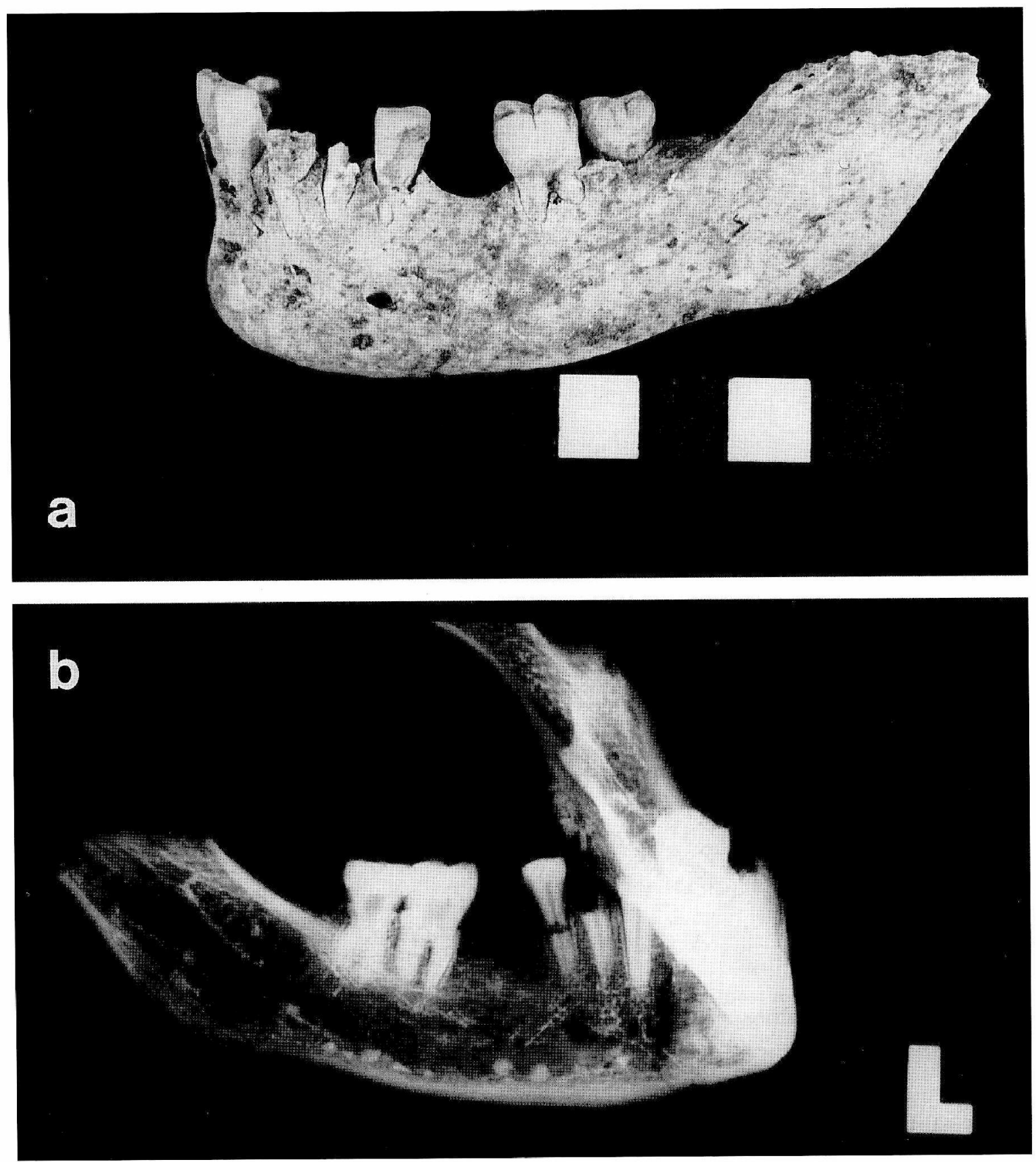

Fig. 5. Photograph (a) and radiograph (b) of the left mandible of specimen 2113-575. Note the complete resorption and remodeling of the alveolar region of the first molar and the lack of root tips in the radiograph. Seale in centimeters.

caries on $\mathrm{RM}_{1}$. Second, the adult shown in Figure 6 exhibits complete destruction of the $\mathrm{RM}_{1}$ crown. And third, the mandible shown in Figure 5 is a good example of the complete remodeling of the alveolus common to this series. It is interesting to note that after some uncertain age the loss of teeth seems to slow. In several specimens from Samad, the first molar has been lost for some time, but the other molars remain functional. One would think that if dates were eaten regularly throughout life their detrimental effect on the teeth would continue. It could be that dates were in some instances primarily eaten 


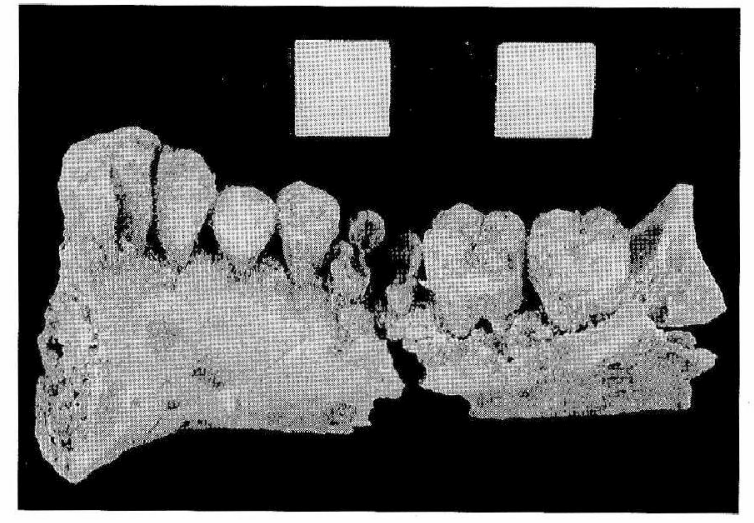

Fig. 6. Right mandible of specimen 2113-751 with complete carious destruction of the crown of the lower right first molar, Scale in centimeters.

by children as sweets. Although there is no documentation for this other than the observations of the skeletal record, it would account for the numbers of young people with destructive caries as well as for the adults with only the first molar lost.

The question of whether tooth extraction was practiced in the prehistoric Arabian peninsula area is open to debate. Hojgaard's (1980b, 1986) radiographic study led her to believe that early Bahrainians frequently removed teeth damaged by caries. However, Littleton and Frohlich (1989) disagree and feel that tooth loss on Bahrain was primarily through natural processes. Radiographs of mandibuli from Samad reveal no tooth root remnants remaining in the alveoli. When this finding is combined with the advanced tooth crown destruction of $\mathrm{RM}_{1}$ seen in specimen 751 (Fig. 6), a tooth which, had extraction been in use, would probably have been pulled, it appears unlikely that curative extraction was common among the peoples of late Iron Age Samad.

Dental attrition in the sample from Samad is clearly demarcated between the anterior and posterior dentition. Molar wear is frequently so slight that the third molars are fully occluded but wear on M2 is nearly unnoticeable. In several instances the wear pattern of the molars is one in which the cusps are rounded with no clear facets and the tooth is glossy, showing only fine scratches under magnification. In contrast, the incisors and canines exhibit such extreme wear that frequently only a ring of enamel remains on the tooth. For the Samad series it appears that the extreme anterior wear is due to mastication-induced attrition. This is contrary to explanations advanced by Littleton and Frohlich (1993), in which heavy anterior wear for dentitions from the Arabian peninsula is attributed to nonmasticatory uses on the basis of unique wear patterns. As only one lower premolar (out of 101 I1-P4 teeth) has wear which could be the result of such use, it seems more probable that the light posterior vs. heavy anterior wear profile found at Samad derives from early AMTL of the molar teeth with loss of functional mastication and subsequent use of the anterior teeth for chewing.

\section{CONCLUSIONS}

There is a long history of human habitation along the Wadi Samad. Beginning in the early third millennium BC with copper mining and smelting up through modern times, occupation has seemingly been continuous (Potts, 1990). Through this time, subsistence has changed from a broad-based hunting and gathering economy to one reliant on agriculture, and this change can be seen in the dentition of the early inhabitants. The majority of human skeletal material comes from the Bronze and Iron Age occupations of Maysar and Samad, where differences in the dental pathology profiles between the two groups are apparent (Kunter, 1981, 1983). Particularly in the areas of caries prevalence and antemortem tooth loss, the late Iron Age inhabitants of Samad exhibit higher frequencies than their Bronze Age forebears.

In contrast to earlier and contemporary coastal settlements with marine-based subsistence where caries and AMTL frequencies are low (Hojgaard, 1980a; Macchiarelli, 1989), the later inhabitants of the interior regions of Oman experienced severe dental pathology associated with the type of agriculture practiced. With the advent of, first, graberband irrigation and, second, about $1000 \mathrm{BC}$, the appearance of the falaj (Potts, 1990), the use of date palms to produce shade and thereby alter the climatic conditions became prevalent. Although dates are nutritious, they are also high in fermentable carbohydrates and have been shown to be 
highly cariogenic. As is apparently the case at other contemporary sites from the Arabian peninsula, it appears that the high caries and AMTL rates found among the last of the pre-Islamic groups to inhabit the Wadi Samad can be attributed to the consumption of this fruit.

Who was eating dates is a question that remains. It seems from the material studied for this report that, because of the instances of early caries found affecting M1s but not necessarily other molars, the young were the primary consumers. This does not mean that adults were not eating dates, as there are historical records that confirm this (Potts 1990), but that they were possibly not consuming them in either the quantity or with the frequency that children were.

\section{ACKNOWLEDGMENTS}

We thank Dan Steinberg and the staff of the Radiology Department at Sacred Heart Hospital (Eugene, OR) for their time and expertise.

\section{LITERATURE CITED}

Berthoud T, Cleuziou S. 1980. Farming communities of the Oman peninsula and the copper of Makkan. J Oman Studies 6:239-246.

Cleuziou S, Tosi M. 1989. The south-eastern frontier of the ancient Near East. In: Frifelt K, Sorensen P, editors. South Asian Archaeology 1985. London: Cruzon Press. p 14-47.

Costa PM. 1980. Notes on settlement patterns in traditional Oman. J Oman Studies 6:247-268.

Doe DB. 1977. Gazetteer of sites in Oman, 1976. J. Oman Studies 3:35-57.

Featherstone JDB. 1987. The mechanism of dental decay. Nutrition Today 22:10-16.

Frayer DW. 1988. Caries and oral pathologies at the Mesolithic sites of Muge: Cabeco da Arruda and Moita do Sebastiao. Trab Anthropol e Ethnol 27:9-25.

Frifelt K. 1989. Third millennium irrigation and oasis culture in Oman. In: Kenoyer JM, editor. Old problems and new perspectives in the archaeology of South Asia. Wisconsin archaeological reports, vol 2. Madison: Department of Anthropology, University of Wisconsin. p 105-113.

Hastings A, Humphries JH, Meadow RH. 1975. Oman in the third millennium BCE. J Oman Studies 1:9-56.

Hojgaard K. 1980a. Dentition on Umm an-Nar (Trucial Oman) 2500 B.C. Scand J Dent Res 88:355-364.

Hojgaard K, 1980b. Dentition on Bahrain, 2000 B.C. Scand J Dent Res 88:467-475.

Hojgaard K. 1986. Dental anthropological investigations on Bahrain. In: al-Khalifa S, Rice M, editors. Bahrain through the ages: the archaeology. London: KPI. p 64-72.

Humphries JH. 1974. Harvard archaeological survey in Oman: some later prehistoric sites in the Sultanate of Oman. Proc Sem Arab Stud 4:49-77.

Jackes M, Lubell D. 1995. Dental pathology and diet: second thoughts. In: Otte $\mathrm{M}$, editor. Nature et culture, colloque de Liege (13-17 Decembre 1993). Liege: E.R.A.U.L. p 457-480.

Kunter M. 1981. Bronze- und eisenzeitliche Skelettfunde aus Oman. Homo 32:197-210.

Kunter M. 1983. Chronologische und regionale unterschiede bei pathologischen zahnbefunden auf der Arabischen halbinsel. Archaologisches Korrespondenzblatt 13:339-343.

Larsen CS, Shavit R, Griffen MC. 1991. Dental caries evidence for dietary change: an archaeological context. In: Kelley MA, Larsen CS, editors. Advances in dental anthropology. New York: Wiley-Liss. p 179202.

Littleton J, Frohlich B. 1989. An analysis of dental pathology and diet on historic Bahrain. Paleorient 15:59-75.

Littleton J, Frohlich B. 1993. Fish-eaters and farmers: dental pathology in the Arabian Gulf. Am J Phys Anthropol 92:427-447.

Lukacs JR. 1985. Tooth size variation in prehistoric India. Am Anthropol 87:811-825.

Lukacs JR. 1989. Dental paleopathology: methods of reconstructing dietary patterns. In: Iscan MY, Kennedy KAR, editors. Reconstruction of life from the skeleton. New York: Alan R. Liss. p 261-286.

Lukacs JR. 1992. Dental paleopathology and agricultural intensification in South Asia: new evidence from Bronze Age Harappa. Am J Phys Anthropol 87:133150.

Lukacs JR. 1995. The 'Caries Correction Factor': a new model of calibrating dental caries rates to compensate for antemortem loss of teeth. Int J Osteoarchaeology 5:151-156.

Lukaes JR, Hemphill BE. 1992. Dental anthropology. In: Kennedy KAR, editor. Human skeletal remains from Mahadaha: A Gangetic Mesolithic Site. Ithaca, NY: Cornell University South Asia Occasional Papers and Theses No. 11. p 157-270.

Lukacs JR, Minderman LL. 1992. Dental pathology and agricultural intensification from Neolithic to Chalcolithic periods at Mehrgarh (Baluchistan, Pakistan). In: Jarrige C, editor. South Asian Archaeology 1989. Madison: Prehistory Press. p 167-179.

Lukacs JR, Pal JN, 1993. Mesolithic subsistence in North India: inferences from dental attributes. Curr Anthropol 34:745-765.

Lukacs JR, Schultz M, Hemphill BE, 1989. Dental pathology and dietary patterns in Iron Age northern Pakistan. In: Frifelt K, Sorensen P, editors. South Asian Archaeology 1985. London: Curzon Press. p $475-496$.

Macchiarelli R. 1989. Prehistoric "fish-eaters" along the Eastern Arabian coasts: dental variation, morphology, and oral health in the Ra's al-Hamra community (Qurum, Sultanate of Oman, 5th-4th millennia BC). Am J Phys Anthropol 78:575-594.

Mandel ID. 1979. Dental caries. Am Sci 67:680-688.

Molnar S. 1971. Human tooth wear, tooth function and cultural variability. Am J Phys Anthropol 34:175-190.

Newbrun E. 1982. Sugar and dental caries: a review of human studies. Science 217:418-423.

Potts D'I: 1990. The Arabian Gulf in antiquity. Oxford: Oxford University Press.

Potts DT, 1993. The Late Prehistoric, Protohistoric, and Early Historic periods in eastern Arabia (ca. 50001200 B.C.). J World Prehistory 7:163-212.

Powell ML. 1985. The analysis of dental wear and caries for dietary reconstruction. In: Gilbert RI, Mielke LJH, editors. The analysis of prehistoric diets. New York: Academic Press. p 307-338.

Scott EC. 1979. Dental wear scoring technique. Am J Phys Anthropol 51:213-218. 
Stephan RM. 1966. Effects of different types of human foods on dental health in experimental animals. I Dent Res 45:1551-1561.

Tosi M. 1986. The emerging picture of prehistoric Arabia. Ann Rev Anthropol 15:461-490.

Vogt B. 1984. 1st mill. B.C. graves and burial customs in the Samad area (Oman). In: Boucharlat R, Salles J-F, editors. Arabie Orientale, Mesopotamie et Iran Meridional: de l'age du fer au debut de la periode Islamique. Paris: Editions Recherche sur les Civilisations, Mem. 37. p 271-284.
Vogt B, Haser J, Kastner JM, Schutkowski H, Velde C. 1989. Preliminary remarks on two recently excavated tombs in Shimal, Ras al-Khaimah (United Arab Emirates). In: Frifelt K, Sorensen P, editors. South Asian Archaeology 1985. London: Curzon Press. p 62-73.

y'Edynak G. 1992. Dental pathology: a factor in postPleistocene Yugoslav dental reduction. In: Lukacs JR, editor. Culture, ecology, and dental anthropology. Delhi: Kamla Raj. p 133-144.

Yule P. 1993. Excavations at Samad Al Shan 1987-1991, summary. Proc Sem Arab Studies 23:141-153. 